Article

\title{
Early Life Vitamin C Deficiency Does Not Alter Morphology of Hippocampal CA1 Pyramidal Neurons or Markers of Synaptic Plasticity in a Guinea Pig Model
}

\author{
Stine N. Hansen ${ }^{1}$, Jane M. Bjørn Jørgensen ${ }^{1}$, Jens R. Nyengaard ${ }^{1,2}$, Jens Lykkesfeldt ${ }^{1}{ }^{(\mathbb{D})}$ and \\ Pernille Tveden-Nyborg ${ }^{1, *}$ \\ 1 Section for Experimental Animals, Department of Veterinary and Animal Sciences, University of \\ Copenhagen, Ridebanevej 9, 1870 Frederiksberg, Denmark; snoha@sund.ku.dk (S.N.H.); \\ jane_bjoern@hotmail.com (J.M.B.J.); jrnyengaard@clin.au.dk (J.R.N.); jopl@sund.ku.dk (J.L.) \\ 2 Core Center of Molecular Morphology, Section for Stereology and Microscopy, Centre for Stochastic \\ Geometry and Advanced Bioimaging, Department of Clinical Medicine, Aarhus University, \\ Noerrebrogade 44, Building 10G, 3rd Floor, 8000 Aarhus, Denmark \\ * Correspondence: ptn@sund.ku.dk; Tel.: +45-3533-3167
}

Received: 12 May 2018; Accepted: 7 June 2018; Published: 8 June 2018

\begin{abstract}
Approximately 15\% of the Western world population, including pregnant women and their children, is characterized as vitamin C (vitC) deficient. In guinea pigs, early life vitC deficiency causes spatial memory deficits, decreased hippocampal volume and neuron numbers, in otherwise clinically healthy animals. We hypothesized that vitC deficiency leads to decreased brain-derived neurotrophic factor and synaptic plasticity markers in selected brain areas (frontal cortex, hippocampus and striatum) and cause morphological changes in cornu ammonis 1 pyramidal neurons of the hippocampus either through a direct effect or indirectly by increased oxidative stress. Fifty-seven female guinea pigs were allocated to three groups receiving either 1390,100 or $0-50 \mathrm{mg} v \mathrm{vit} / \mathrm{kg}$ feed for 11 weeks. Dietary vitC levels were reflected in the plasma, cortical and adrenal gland levels, however, redox imbalance was only present in the adrenal glands allowing for the investigation of a direct influence of vitC deficiency on the chosen parameters in the brain. Synaptic plasticity markers were not affected in the investigated brain areas and no differences in isolated pyramidal neuron morphology was recorded. Based on our findings, it appears that vitC deficiency may primarily elicit impaired neuronal function through increased levels of oxidative stress.
\end{abstract}

Keywords: vitamin C deficiency; cavia porcellus; neuronal morphology; synaptic plasticity

\section{Introduction}

The developing brain is particularly susceptible to oxidative stress due to a high cellular metabolic activity and immature antioxidant systems [1-3]. During this sensitive period, malnutrition has been shown to elicit a negative impact on cognitive function, brain morphology, neuronal development and maturation [4-6]. In the Western world, vitamin C (vitC) deficiency is relatively common, with an estimated prevalence of about 15\% [7-9], including pregnant women and children [10-12]. VitC is an essential micronutrient with strong antioxidant properties and the brain displays surprisingly high levels in comparison with other organs $[13,14]$. During prolonged depletion of dietary vitC, the levels in the brain only decline to approximately $25 \%$ of saturated levels, despite close to total exhaustion in most other organs, emphasizing the brain's unique ability to preserve high vitC levels [15,16]. In addition to being an efficient quencher of free radicals, vitC is also a specific co-factor in several cellular pathways 
e.g., the recycling of tetrahydrobiopterin (BH4), involved in the synthesis of the monoaminergic neurotransmitters, and acts as a key participant in glutamatergic neurotransmission/glutamate re-uptake [17-19].

In guinea pigs, early life vitC deficiency increases oxidative stress in the brain resulting in spatial memory deficits, reduced hippocampal volume and neuron numbers, as well as a suggested decrease in neuronal migration in the dentate gyrus [16,20-22]. Furthermore, vitC transport to the brain is essential for perinatal survival in mice $[23,24]$, and induced deficiency has been shown to reduce functional performance in the L-gulono- $\gamma$-lactone oxidase knockout mice $\left(\right.$ Gulo $\left.^{-1-}\right)[25,26]$. These studies stress the importance of vitC in the brain and highlight the negative consequences of deficiency during cerebral development; however, the underlying mechanisms behind vitC deficiency promoted deficits in the brain are currently not sufficiently elucidated.

Synaptic plasticity and dendrite development are key neuronal features in memory formation [27-30]. VitC supplementation to in vitro cultured neurons exposed to a peroxide insult induces brain derived neurotrophic factor (BDNF) [31], while total cessation of vitC supplementation leads to increased oxidative stress and decreased BDNF in the brain in vivo [32]. In the developing brain, BDNF is an important growth factor promoting neuronal survival, dendrite development and synaptic plasticity [33], and plays an essential role in memory formation, including spatial memory [33,34]. Thus, perturbation of the BDNF pathway may be an important contributor to the dysfunctions in spatial memory reported in marginally vitC deficient guinea pigs [20]. This may be by the direct influence of low vitC on BDNF or secondarily through increased oxidative stress. In addition, the active uptake of reduced vitC, ascorbate (Asc) in neurons, achieved through the sodium-dependent vitC transporter 2 (SVCT2), has been shown to be important for neuronal maturation, glutamatergic function, and dendrite morphology and complexity [35-37], highlighting another, potentially direct, effect of vitC deficiency on synaptic plasticity, dendrite development and subsequent neuronal signaling.

The current study investigated the hypothesis that early life vitC deficiency increases oxidative stress and decreases the levels of BDNF in the frontal cortex (FC), the hippocampus (Hip) and the striatum (Stri), which are all regions that are interconnected and involved in spatial memory, motor function, goal-directed behavior and decision making [38-40] (Figure 1). Decreased levels of BDNF may decrease protein levels and/or phosphorylation of downstream molecular markers $\mathrm{Ca}^{2+}$-calmodulin-dependent kinase II (CAMKII) and synapsin 1, promoting negative effects on synaptic plasticity, dendrite development and neurotransmission [3,41]. Furthermore, vitC deficiency might decrease signal transmission and spatial memory formation by reducing arborization and dendritic spine development of the hippocampal cornu ammonis 1 (CA1) pyramidal neurons, known to be vulnerable to oxidative stress, [42-45]. Two different degrees of vitC deficiency were compared to controls receiving high levels of vitC, enabling the assessment of a putative dose-related response on the investigated markers. 


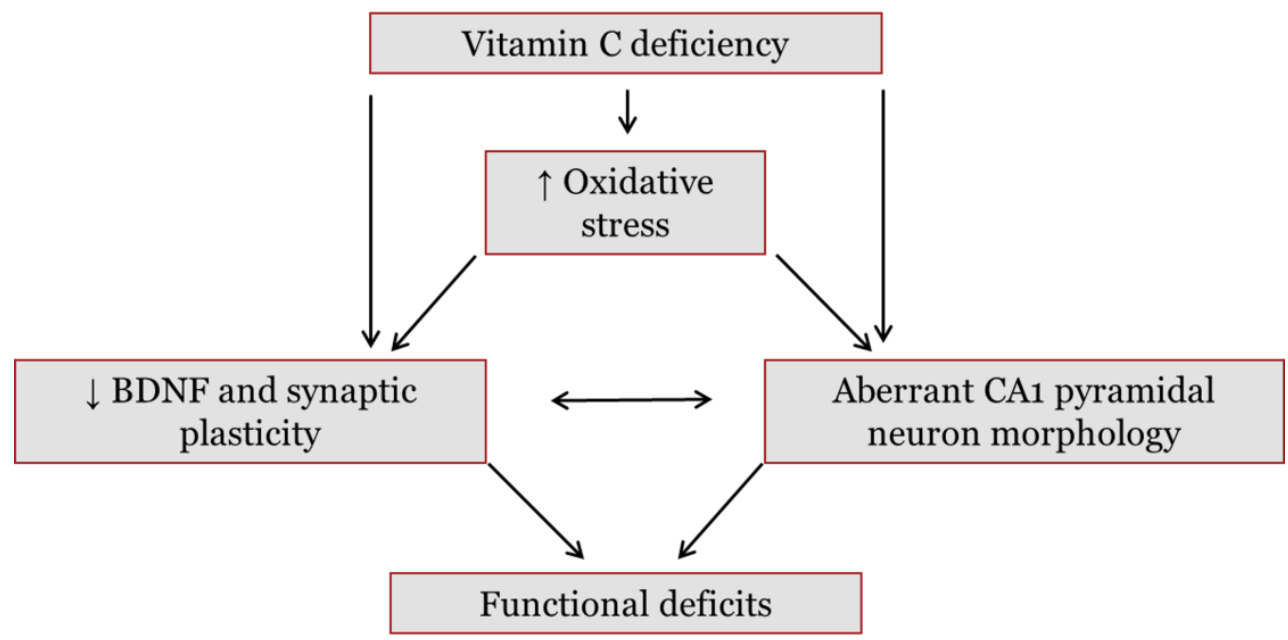

Figure 1. Hypothesized pathways through which vitamin $C$ (vitC) deficiency may cause functional deficits in the brain. Reduced levels of vitC during deficiency may disturb redox balance and subsequently promote oxidative stress in the brain. In addition, vitC deficiency may exert a direct effect on brain function. Both vitC deficiency and increases in oxidative stress have been found to lower levels of brain-derived neurotrophic factor (BDNF) in the brain. A decrease in BDNF, and subsequent negative effects on downstream pathways, may reduce synaptic plasticity. Synaptic plasticity is crucial in memory formation and cognitive functions; hence, dysfunction may lower signal transmission and induce functional deficits. BDNF is also involved in neuronal arbor growth and a reduction may further induce aberrant dendrite development of hippocampal cornu ammonis (CA) 1 pyramidal neurons. These neurons are crucial in memory functions and have been found to be susceptible to increased oxidative stress and states of malnutrition. Collectively, vitC deficiency is hypothesized to cause changes in synaptic plasticity and neuronal morphology, potentially disrupting brain functionality.

\section{Materials and Methods}

\subsection{Animals}

All in vivo experiments were approved by the Danish Animal Experiments Inspectorate (License number 2012-15-2934-00205) under the Ministry of Environment and Food and in accordance with EU directive 2010/63/EU and approved by the Animal Care and Use Committee (IACUC, University of Copenhagen, Faculty of Health Sciences) on 11 March 2016 (project number P16-210). All animals were inspected daily by trained personnel and group-housed in floor pens with ad libitum access to feed, hay and water. In total, 57 female Dunkin Hartley guinea pigs (Envigo, Venray, The Netherlands) at seven days of age were weight-stratified into three dietary groups ( $n=19$ /group) receiving a standard guinea pig maintenance chow (prod. code S9406; ssniff Spezialdiäten GmbH, Soest, Germany) differing only in vitC content. The vitC was added as phosphorylated ascorbate (Stay-C) to extend stability. The total ascorbate content of the feed was subsequently determined by post production analysis. The respective experimental groups received: $1390 \mathrm{mg}$ vitC $/ \mathrm{kg}$ feed by analysis (Ctrl), $100 \mathrm{mg}$ vitC $/ \mathrm{kg}$ feed (Def) and 0-50 mg vitC/kg feed (Sev_def) (ssniff Spezialdiäten GmbH, Soest, Germany). The levels of 100 and $50 \mathrm{mg}$ vitC/ $\mathrm{kg}$ feed were obtained by titration of $123 \mathrm{mg}$ vitC $/ \mathrm{kg}$ feed (by analysis) with $0 \mathrm{mg}$ vitC $/ \mathrm{kg}$ feed. The Sev_def group was kept on $0 \mathrm{mg}$ vitC $/ \mathrm{kg}$ feed for 16 days, until the first animals showed signs of weight stagnation (a pre-scorbutic clinical sign) after which the entire group was immediately transferred to $50 \mathrm{mg}$ vitC $/ \mathrm{kg}$ feed. Three Sev_def animals received an oral dose of softened vitC containing feed on day 16 and 17 to alleviate pre-scorbutic symptoms. The vitC levels of the Ctrl and Def diets were based on previously published data, ensuring vitC levels in Ctrl and low, albeit non-scorbutic levels in Def animals [13,20,21]. The Sev_def group was included in the study to increase effects of low vitC by first inducing a severe, borderline scorbutic vitC deficiency through total 
dietary depletion and subsequently keeping the animals on a low but non-scorbutic vitC containing diet. All animals were weight-monitored weekly, except for Sev_def animals, which were weighed every other day during the first 16 days. Apart from the three Sev_def animals which were briefly treated for symptoms of scurvy to a full recovery, no other clinical signs of decreased animal welfare were recorded during the study period.

After 11 weeks on the diet, the animals were sedated with $0.2 \mathrm{~mL} / \mathrm{kg}$ butorphanol (Torbugesic, Scanvet, Fredensborg, Denmark) and anaesthetized with 3-5\% isoflurane (Isoba Vet, Intervet International, Boxmeer, The Netherlands), until cessation of voluntary reflexes after which an intra-cardiac blood sample was obtained and plasma subsequently collected as previously described [46]. The animals were euthanized by decapitation and the brains were removed, rinsed in ice-cold PBS, weighed and divided into hemispheres. The right hemispheres from 27 randomly chosen animals were allocated to another study. For the remaining 30 animals, the right hemispheres from Ctrl and Sev_def were preserved for the Golgi-analysis, while the right hemispheres from the Def group were not included in this part of the study. The left hemispheres from all animals in the three groups were divided into FC, Hip, Stri (defined by anatomical fix-points with reference to the rat brain [47]) and the residual cerebral cortex, and immediately snap-frozen in liquid nitrogen. The adrenal glands were removed, rinsed in PBS; the left was snap-frozen in liquid nitrogen and the right fixated in $4 \%$ paraformaldehyde for future analysis.

\subsection{Biochemistry}

Plasma levels of total vitC, dehydroascorbate (DHA), malondialdehyde (MDA), $\alpha$ - and $\gamma$-tocopherol, $\mathrm{BH} 4$ and dihydrobiopterin (BH2) were measured. In tissue samples, the residual cerebral cortex and adrenal gland, analyses of vitC, DHA, glutathione (GSH), glutathione disulfide (GSSG), superoxide dismutase (SOD), MDA (not adrenal glands), $\alpha$ - and $\gamma$-tocopherol were conducted. Both plasma and tissue samples were analyzed as previously described [22,46,48-50].

Briefly, plasma samples for total vitC and DHA were stabilized 1:2 with 10\% meta-phosphoric acid and analyzed by electrochemical detection on HPLC. DHA\% was calculated as the percentage of total vitC, which constitutes DHA. MDA was measured by fluorometric detection on HPLC. BH4 was stabilized with $4 \%$ dithioerythritol and quantified by fluorometric detection on HPLC. For tissue samples the tissue was homogenized 1:10 in PBS and for total vitC, DHA, GSH and GSSG, the samples were stabilized 1:2 with 10\% meta-phosphoric acid. GSH and GSSG were measured using spectrofluorometry and vitC and DHA by electrochemical detection on HPLC. For SOD, a Ransod kit was used. $\alpha$ - and $\gamma$-tocopherol were measured by HPLC using electrochemical detection.

\subsection{Protein Extraction}

The protein extraction was performed on ten randomly chosen animals from each group as previously described [51]. Briefly, $40 \mathrm{mg}$ of tissue from each of FC, Hip and Stri was dissected on ice. The tissue samples were homogenized using a Potter-Elvehjem in $500 \mu \mathrm{L}$ RIPA buffer $(50 \mathrm{mmol} / \mathrm{L}$ tris pH 8.0, $150 \mathrm{mmol} / \mathrm{L}$ sodium chloride, $1 \%$ Triton $\mathrm{X}-100,0.5 \%$ sodium deoxycholate and $0.1 \%$ sodium dodecyl sulfate) with 1:100 protease inhibitor cocktail (Sigma-Aldrich, Darmstadt, Germany) and 1:100 phosphatase inhibitor cocktail (Sigma-Aldrich, Darmstadt, Germany). The samples were centrifuged for $10 \mathrm{~min}$ at $12,000 \mathrm{rpm}$ at $4{ }^{\circ} \mathrm{C}$ and the protein extract was stored at $-80{ }^{\circ} \mathrm{C}$ in aliquots. Protein concentration was determined by a commercial BCA kit according to manufacturer's instructions (Merck Millipore, Darmstadt, Germany).

\subsection{ELISA}

BDNF levels were analyzed in FC, Hip and Stri using a commercial ELISA kit (SEA011Gu, Cloud-Clone Corp, Houston, TX, USA) as instructed by the manufacturer. All samples were diluted 1:20 in sterile PBS as determined by a dilution series to obtain an optical density close to the center of the linear part of the standard curve. All results were normalized to protein concentration. Four 
animals across all three groups had to be excluded from the FC analysis and three from the Hip for technical reasons.

\subsection{Western Blotting}

Ten $\mu$ g of protein from each of FC, Hip and Stri were adjusted to a volume of $11.25 \mu \mathrm{L}$, before adding $3.75 \mu \mathrm{L}$ Laemmli buffer (Bio Rad, Hercules, CA, USA) with 1:10 mecaptoethanol (Sigma-Aldrich, Darmstadt, Germany). The samples were denatured at $70{ }^{\circ} \mathrm{C}$ for $10 \mathrm{~min}$ before transfer to a $7.5 \%$ Criterion $^{\mathrm{TM}} \mathrm{TGX}^{\mathrm{TM}}$ Precast Midi Protein Gel, 26 well, $15 \mu \mathrm{L} /$ well (Bio Rad, Hercules, CA, USA) and the electrophoresis was run for approximately $40 \mathrm{~min}$. Afterwards the proteins were transferred to a PVDF membrane [51]. All samples were run in duplicates and normalized to total protein levels (REVERT ${ }^{\mathrm{TM}}$ Total Protein Stain, Li-Cor, Lincoln, NE, USA). The following antibodies were applied: Anti-synapsin 1 (ab8, Abcam, Cambridge, United Kingdom; 1:1000); anti-CAMKII (Cba-2, Thermo Scientific, Waltham, MA, USA; 1:4000); anti-phosphorylated CAMKII ( $p$-CAMKII) (22B1, Thermo Scientific, Waltham, MA, USA; 1:1000); anti-phosphorylated synapsin 1 ( $p$-synapsin 1) (NB300-181, Novus Biologicals, Littleton, CO, USA; 1:1000). All primary antibodies were incubated at $4{ }^{\circ} \mathrm{Co} / \mathrm{n}$. As secondary IRDye ${ }^{\circledR} 800 \mathrm{CW}$ Donkey-anti-Rabbit IgG (Li-Cor, Lincoln, NE, USA; 1:15,000) and IRDye ${ }^{\circledR}$ 680RD Donkey-anti-Mouse IgG (Li-Cor, Lincoln, NE, USA; 1:15,000) were applied for one hour at RT. The analyses were done using Image Studio 5.2 (Li-Cor, Lincoln, NE, USA) by an observer blinded to the experimental group. Examples of Western blots positive for the selected markers, are provided in Figure 2.

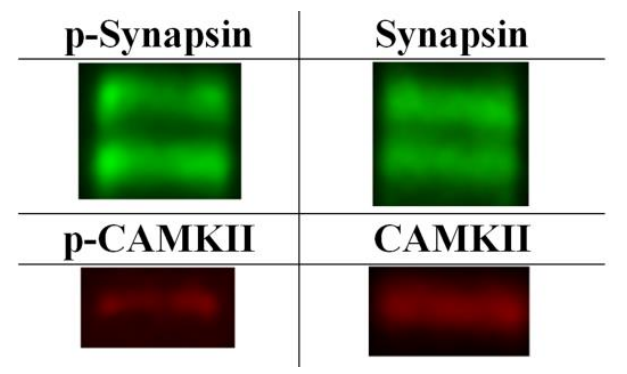

Figure 2. Examples of Western blots of $p$-/synapsin 1 and $p$ - $/ \mathrm{Ca}^{2+}$-calmodulin-dependent kinase II. The figure depicts examples of the Western blots of the four synaptic plasticity markers investigated. The two bands seen in the $p$-synapsin and synapsin Western blots (70 and $74 \mathrm{kDa}$ respectively) are consistent with splice variants as confirmed by manufacturer. P-CAMKII and CAMKII were detected around $50 \mathrm{kDa}$ in accordance with previous findings.

\subsection{Golgi-Staining and Section Processing}

Only Ctrl and Sev_def animals were used for the Golgi-staining and 3D reconstruction of neurons. To Golgi-stain the right hemispheres, a commercial kit was purchased (FD Rapid GolgiStain ${ }^{\mathrm{TM}}$, FD NeuroTechnologies, Inc., Colombia, MD, USA) and the staining performed as per manufacturer's instructions [52]. In summary: The hemispheres were stored in A + B solution for 14 days with a solution change after $24 \mathrm{~h}$ and then transferred to $\mathrm{C}$ solution for seven days with a solution change after $24 \mathrm{~h}$. The hemispheres were then snap-frozen in isopropanol and stored at $-80{ }^{\circ} \mathrm{C}$ until further processing.

The hemispheres were mounted on a HM 569 M Cryostat (Mikrom, Walldorf, Germany) and the Hip was cut into $200 \mu \mathrm{m}$ coronal sections in its entirety. The sections were mounted on $2 \%$ gelatin-coated slides and left to dry for one hour at RT after which they were rinsed in miliQ water and placed in $\mathrm{D}+\mathrm{E}$ solution for $10 \mathrm{~min}$, before being dehydrated in alcohol, cleared in xylene and cover slipped. 


\subsection{Image Acquisition and Analysis}

Z-stacks of neurons with somas lying within the stratum pyramidale of the CA1 area of the Hip were captured with newCAST, VIS (Visiopharm, Hoersholm, Denmark) using Olympus BX50F microscope (Olympus Optical co., LTD., Tokyo, Japan) and 60X oil objective (PlanApo, NA 1.40, Oil, Olympus, Japan) applying a step size of $1 \mu \mathrm{m}[52,53]$. Neurons were preferentially selected with the soma situated in the middle of the z-axis of the section (between 80 and $150 \mu \mathrm{m}$ post-dehydration). To reconstruct and analyze the neurons the automatic filament tracer in Imaris (Bitplane, Zürich, Switzerland) was applied. From each animal, five to seven apical and basal dendritic trees, respectively, were analyzed and averaged by an observer blinded to the experimental group [52,53]. The Sholl analysis was conducted in the program by concentric circles with a radius difference of $20 \mu \mathrm{m}$ radiating from the center of the soma [52]. An overview of the measured morphological parameters and the expected outcome of vitC deficiency is shown in Table 1.

Table 1. Parameters included in the morphological analysis of cornu ammonis 1 pyramidal neurons. Vitamin C deficiency was expected to cause aberrant neuron morphology either directly or through subsequent oxidative stress thereby decreasing dendrite branching and length of cornu ammonis 1 pyramidal neurons causing an overall decrease in filament length. Furthermore, deficiency induced spine degeneration was expected to reduce total spine numbers and spine density, while also affecting the morphology of the spines. The change in spine morphology inflicted by deficiency was hypothesized to cause a shift towards a more immature/degenerated state of the dendritic spines with decreases in volume, area, diameter and shortening of the neck. Spine length could be increased due to an increase of immature filopodia or decreased due to degeneration [54,55]. The descriptions of the morphological parameters are based on descriptions in the Imaris manual provided by Bitplane.

\begin{tabular}{ccc}
\hline Parameter & Explanation & $\begin{array}{c}\text { Expected Outcome of } \\
\text { Vitamin C Deficiency }\end{array}$ \\
\hline Dendrite length & The sum of the lengths of all dendrites on a neuron & $\downarrow$ \\
Dendrite diameter & The mean diameter within a dendrite & $\leftrightarrow$ or $\downarrow$ \\
Dendrite volume & The volume of a dendrite & $\leftrightarrow$ or $\downarrow$ \\
Branch numbers & The number of dendrite branches on an neuron & $\downarrow$ \\
Spine number & The number of spines on the entire neuron & $\downarrow$ \\
Spine density & The number of spines per 10 rm dendrite & $\downarrow$ \\
Filament length & The sum of dendrite length and spine length & $\downarrow$ \\
Spine length & The length of the spines & or $\downarrow$ \\
Spine diameter & The mean of the spine diameter & $\downarrow$ \\
Spine area & The surface area of the spine & $\downarrow$ \\
Spine volume & The volume of the spine & $\downarrow$ \\
Spine neck length & The length of the spine neck & $\downarrow$ \\
Spine neck diameter & The diameter of the spine neck & $\downarrow$ \\
Spine neck volume & The volume of the spine neck & $\downarrow$ \\
\hline
\end{tabular}

\subsection{Statistical Analysis}

The data was analyzed in GraphPad Prism 7 (GraphPad Software, La Jolla, CA, USA) either by repeated-measures two-way ANOVA, one-way ANOVA or Student's $t$-test. Equality of variances was assessed by the Brown-Forsythe test, while normal distribution was assessed by the D'Agostino \& Pearson normality test and histograms. In the event of nonhomogeneous variances, the data was log-transformed or a nonparametric test was applied. Tukey's or Dunn's multiple comparisons test were applied to correct for multiple comparisons in the biochemical and Western blotting data. Results are presented as mean $\pm \mathrm{SD}$, or median ( $25 \%$, $75 \%$ quartiles). A $p$-value $<0.05$ was considered statistically significant. As DHA\% is calculated as (total vitC - Asc)/total vitC $\times 100$ [48], DHA\% may-when close to zero-occasionally give rise to negative values. In this study, negative values have been set to zero, while statistics have been performed on the original data to preserve normal distribution and variance. 


\section{Results}

\subsection{Animals}

There was a significant impact of time and diet on the bodyweight (time $p<0.0001$; diet $p=0.0436$; interaction $p<0.0001)$. The Sev_def group displayed mild growth retardation, when compared with Ctrl from week 4 to week 8 (week $4, p=0.0038$; week 5, $p=0.0078$; week 6, $p=0.0036$; week 7, $p=0.0021$; week $8, p=0.0170$ ) but caught up in week 9 and 10 (Figure 3). At study termination, there was a significant difference in the bodyweight of both Def and Sev_def compared to Ctrl (Def $p=0.0416$; Sev_def $p=0.0170)$.

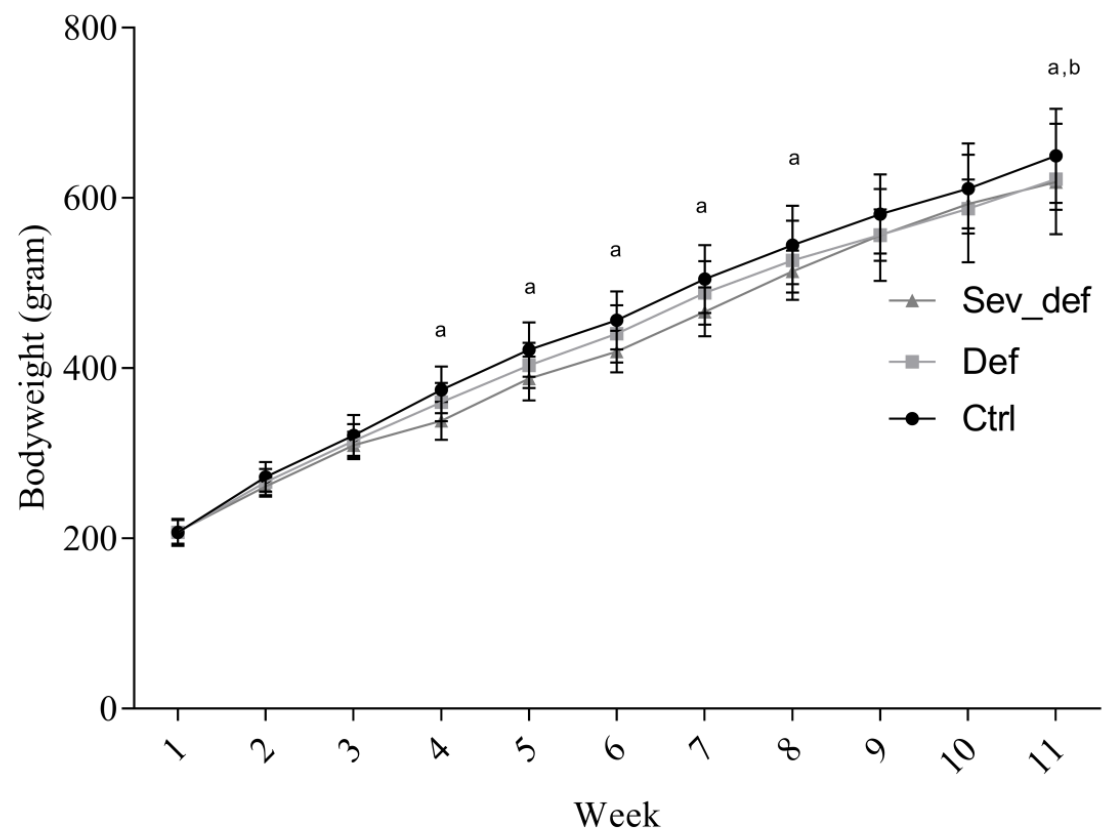

Figure 3. Changes in guinea pig bodyweight during the study. The Sev_def group showed mild growth retardation from week 4 , but caught up with Def animals by week 9 . At termination, there was a significant difference between Ctrl and Def and Sev_def. ${ }^{a}$ Ctrl vs. Sev_def, $p<0.05$; ${ }^{b}$ Ctrl vs. Def, $p<0.05$. Two-way repeated-measures ANOVA with Tukey's multiple comparison correction, $n=19$, mean \pm SD. Ctrl: Control animals, Def: Vitamin C deficient animals, Sev_def: Severely vitamin C deficient animals.

\subsection{Biochemistry}

As expected, the vitC levels in plasma reflected the respective diets of the groups $(p<0.0001)$ : the Def and Sev_def groups had significantly lower plasma levels than the Ctrl $(p<0.0001)$ (Table 2) at euthanasia. The two deficient groups were also significantly different from each other (Def vs. Sev_def $p<0.0001)$. BH4 concentration in plasma was significantly higher in Ctrl than Def and Sev_def $(p<0.0001)$, while Sev_def was significantly lower than Def (Def vs. Sev_def $p=0.031)$ (Table 2). This was also reflected in the $\mathrm{BH} 2 / \mathrm{BH} 4$ ratio, which was significantly lower in Ctrl animals compared to Def and Sev_def $(p<0.0001)$, while there was no difference between the two deficiency groups. There were no differences between the groups in plasma $\alpha$ - and $\gamma$-tocopherol and MDA (Table 2).

Dietary vitC intakes were also reflected in the vitC levels in the cerebral cortex: Sev_def levels were lower than Def $(p<0.0001)$ and both Sev_def and Def levels were lower than Ctrl $(p<0.0001)$ (Table 2). Despite reaching significant differences between groups $(p<0.0001)$, DHA\% was consistently very low and likely negligible (Ctrl vs. Sev_def $p<0.0001$; Def vs. Sev_def $p=0.0413$ ). No other markers showed any differences between the groups (Table 2). 
Table 2. Biochemical parameters of plasma, residual cortex and the adrenal glands.

\begin{tabular}{|c|c|c|c|c|c|}
\hline & Group/Marker & Ctrl $(n=19)$ & Def $(n=19)$ & Sev_Def $(n=19)$ & $\begin{array}{c}\text { One-Way ANOVA or } \\
\text { Kruskal-Wallis Test }\end{array}$ \\
\hline \multirow{7}{*}{ Plasma } & $\operatorname{VitC}(\mu \mathrm{M}) *$ & $43.3 \pm 8.5^{\mathrm{a}}$ & $4.4 \pm 0.91^{b}$ & $2.2 \pm 0.46^{\mathrm{c}}$ & $p<0.0001$ \\
\hline & DHA $(\%)^{\#}$ & $1.9 \pm 2.0$ & $3.0 \pm 3.5$ & $2.8 \pm 3.5$ & NS \\
\hline & BH4 (nM) & $68.3 \pm 8.3^{\mathrm{a}}$ & $47.5 \pm 10.1^{\mathrm{b}}$ & $40.4 \pm 6.4^{\mathrm{c}}$ & $p<0.0001$ \\
\hline & $\mathrm{BH} 2 / \mathrm{BH} 4{ }^{œ}$ & $0.18(0.16 ; 0.22)^{\mathrm{a}}$ & $0.31(0.25 ; 0.43)^{b}$ & $0.36(0.33 ; 0.41)^{b}$ & $p<0.0001$ \\
\hline & $\alpha$-tocopherol $(\mu \mathrm{M})$ & $2.7 \pm 0.8$ & $2.5 \pm 0.7$ & $2.5 \pm 0.7$ & NS \\
\hline & $\gamma$-tocopherol $(\mu \mathrm{M})$ & $0.1 \pm 0.06$ & $0.1 \pm 0.05$ & $0.09 \pm 0.04$ & NS \\
\hline & $\operatorname{MDA}(\mu \mathrm{M})$ & $1.0 \pm 0.1$ & $1.1 \pm 0.2$ & $1.1 \pm 0.2$ & NS \\
\hline \multirow{8}{*}{ Residual cerebralcortex } & $\operatorname{VitC}(\mathrm{nmol} / \mathrm{g})$ & $1320 \pm 254.6^{\mathrm{a}}$ & $753.2 \pm 70.7^{b}$ & $393.6 \pm 91.3^{c}$ & $p<0.0001$ \\
\hline & DHA (\%) œ\# & $2.2(1.6 ; 2.6)$ & $1.6(0.1 ; 1.9)^{b}$ & $0.0(0 ; 0.3)^{\mathrm{c}}$ & $p<0.0001$ \\
\hline & GSH (nmol/g) & $1244 \pm 113.7$ & $1247 \pm 79.0$ & $1244 \pm 76.4$ & NS \\
\hline & GSSG (\%) & $3.7 \pm 1.9$ & $4.0 \pm 1.8$ & $3.9 \pm 1.1$ & NS \\
\hline & $\operatorname{SOD}(\mathrm{U} / \mathrm{g})$ & $235 \pm 54.0$ & $232 \pm 63.3$ & $229 \pm 79.9$ & NS \\
\hline & $\operatorname{MDA}(\mathrm{nmol} / \mathrm{g})^{œ}$ & $165.9(135.1 ; 200.1)$ & $169.5(140.7 ; 203.6)$ & $200.8(152.5 ; 254.9)$ & NS \\
\hline & $\alpha$-tocopherol $(\mathrm{nmol} / \mathrm{g})$ & $12.6 \pm 3.1$ & $11.9 \pm 3.3$ & $11.9 \pm 1.6$ & NS \\
\hline & $\gamma$-tocopherol (nmol/g) & $0.6 \pm 0.2$ & $0.6 \pm 0.2$ & $0.6 \pm 0.2$ & NS \\
\hline \multirow{5}{*}{ Adrenal glands } & $\operatorname{VitC}(\mathrm{nmol} / \mathrm{g})$ & $9571 \pm 1951^{a}$ & $3353 \pm 1606^{b}$ & $2554 \pm 2344^{b}$ & $p<0.0001$ \\
\hline & DHA (\%) & $3.5 \pm 1.9^{\mathrm{a}}$ & $4.8 \pm 2.0^{\mathrm{ab}}$ & $5.7 \pm 2.1^{b}$ & $p=0.0052$ \\
\hline & GSH (nmol/g) & $1531 \pm 107^{\mathrm{a}}$ & $1670 \pm 172^{b}$ & $1745 \pm 180^{b}$ & $p=0.0004$ \\
\hline & GSSG (\%) & $2.1 \pm 1.5$ & $1.8 \pm 1.5$ & $2.1 \pm 1.7$ & NS \\
\hline & $\mathrm{SOD}(\mathrm{U} / \mathrm{g})$ & $180 \pm 55.6$ & $158 \pm 52.0$ & $173 \pm 57.3$ & NS \\
\hline
\end{tabular}

Despite a clear influence of diet on vitamin C levels in plasma, cortex and adrenal glands, only the adrenal glands showed sign of increased oxidative stress. One-way ANOVA or

Kruskal-Wallis with Tukey's or Dunn's multiple comparison tests, $n=19$, mean \pm SD for parametric analysis, if non-parameteric: median $(25 \%$; $75 \%$ quartiles) are reported. * Denotes

$\log$ transformed data. ${ }^{\infty}$ Denotes nonparametric ANOVA. \# Denotes truncated data. Different superscript letters denotes differences between groups. BH2: Dihydrobiopterin, BH4:

Tetrahydrobiopterin, Ctrl: Control animals, Def: Vitamin C deficient animals, DHA: Dehydroascorbate, GSH: Glutathione, GSSG: glutathione disulfide, MDA: Malondialdehyde (MDA),

NS: Not significant, Sev_def: Severely vitamin C deficient animals, SOD: Superoxide dismutase, VitC: Vitamin C. Tissue levels are shown as amount per gram tissue. 
In the adrenal glands, total vitC in Def and Sev_def were significantly lower $(p<0.0001)$, when compared with Ctrl, but there was no difference between Def and Sev_def groups (Table 2). The DHA\% was significantly increased in Sev_def, when compared with Ctrl ( $p=0.0038)$, while GSH was increased in both Def and Sev_def ( $p=0.0220$ and $p=0.0003$, respectively) (Table 2). No other markers showed any differences between the groups.

\subsection{ELISA and Western Blotting}

The ELISA results of BDNF levels in FC, Hip and Stri are shown in Figure 4. No influence of dietary vitC on BDNF was detected in any of the three brain areas. The same was evident for the Western blotting results of synaptic plasticity markers: $p$ - and synapsin $1, p$ - and CAMKII and their respective ratios, where no differences due to vitC deficiency could be detected (Table 3 ).
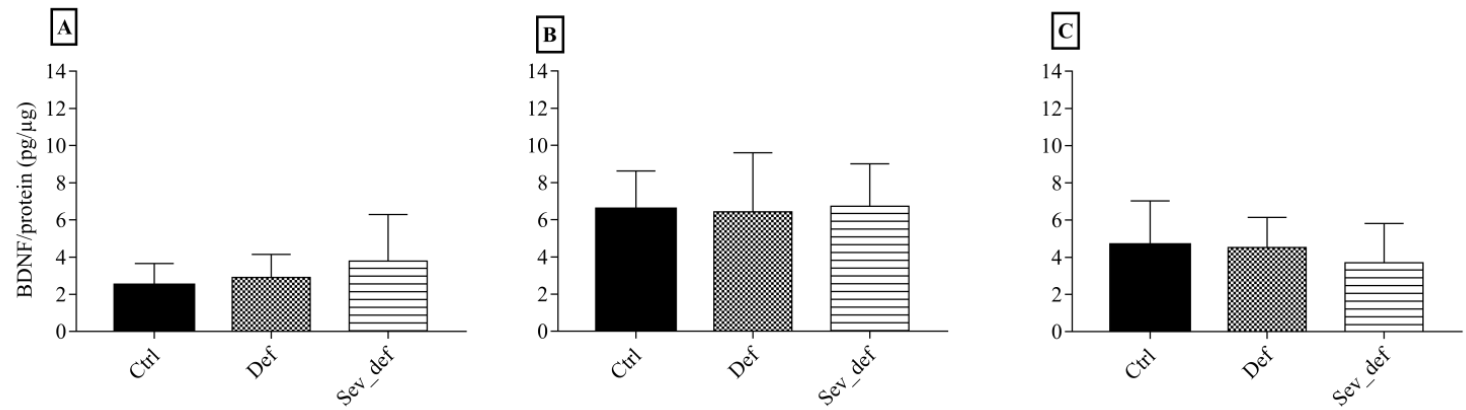

Figure 4. Brain-derived neurotrophic factor levels in the frontal cortex, hippocampus and striatum. Frontal cortex (A), the hippocampus (B) and the striatum (C) as measured by ELISA. No differences between groups were detected in any of the brain areas. One-wayANOVA with Tukey's multiple comparison test, $n=6-10$, mean \pm SD. Ctrl: Control animals, Def: Vitamin C deficient animals, Sev_def: Severely vitamin $C$ deficient animals.

Table 3. Synaptic plasticity markers in the frontal cortex, hippocampus and striatum.

\begin{tabular}{|c|c|c|c|c|c|}
\hline & Group/Marker & Ctrl & Def & Sev_Def & One-Way ANOVA \\
\hline \multirow{6}{*}{ Frontal cortex } & $p$-synapsin 1 & $0.64 \pm 0.20$ & $0.54 \pm 0.15$ & $0.52 \pm 0.15$ & NS \\
\hline & synapsin 1 & $1.41 \pm 0.41$ & $1.66 \pm 0.80$ & $1.36 \pm 0.51$ & NS \\
\hline & $\begin{array}{c}p \text {-synapsin } \\
1 \text { /synapsin } 1\end{array}$ & $0.47 \pm 0.11$ & $0.41 \pm 0.26$ & $0.47 \pm 0.29$ & NS \\
\hline & $p$-CAMKII & $0.08 \pm 0.05$ & $0.05 \pm 0.03$ & $0.06 \pm 0.03$ & NS \\
\hline & CAMKII & $0.39 \pm 0.07$ & $0.38 \pm 0.09$ & $0.35 \pm 0.05$ & NS \\
\hline & p-CAMKII/CAMKII & $0.23 \pm 0.13$ & $0.14 \pm 0.08$ & $0.18 \pm 0.09$ & NS \\
\hline \multirow{6}{*}{ Hippocampus } & $p$-synapsin 1 & $1.24 \pm 0.54$ & $1.19 \pm 0.74$ & $1.11 \pm 0.48$ & NS \\
\hline & synapsin 1 & $1.74 \pm 0.46$ & $1.55 \pm 0.41$ & $1.51 \pm 0.48$ & NS \\
\hline & $\begin{array}{c}p \text {-synapsin } \\
1 \text { /synapsin } 1\end{array}$ & $0.71 \pm 0.26$ & $0.77 \pm 0.39$ & $0.80 \pm 0.43$ & NS \\
\hline & $p$-CAMKII & $0.21 \pm 0.12$ & $0.17 \pm 0.06$ & $0.16 \pm 0.05$ & NS \\
\hline & CAMKII & $0.31 \pm 0.09$ & $0.33 \pm 0.09$ & $0.26 \pm 0.09$ & NS \\
\hline & $p$-CAMKII/CAMKII & $0.71 \pm 0.40$ & $0.56 \pm 0.27$ & $0.63 \pm 0.20$ & NS \\
\hline \multirow{6}{*}{ Striatum } & $p$-synapsin 1 & $0.42 \pm 0.09$ & $0.41 \pm 0.13$ & $0.38 \pm 0.10$ & NS \\
\hline & synapsin 1 & $2.60 \pm 0.92$ & $2.23 \pm 0.73$ & $2.33 \pm 0.37$ & NS \\
\hline & $\begin{array}{c}p \text {-synapsin } \\
1 \text { /synapsin } 1\end{array}$ & $0.18 \pm 0.05$ & $0.20 \pm 0.11$ & $0.17 \pm 0.05$ & NS \\
\hline & $p$-CAMKII & ND & ND & ND & - \\
\hline & CAMKII & $0.06 \pm 0.04$ & $0.06 \pm 0.04$ & $0.04 \pm 0.04$ & NS \\
\hline & p-CAMKII/CAMKII & - & - & - & - \\
\hline
\end{tabular}

All values are in arbitrary units. No differences between groups were detected in any of the markers, in any of the brain areas. One-way ANOVA with Tukey's multiple comparison test, $n=10$, mean \pm SD. NS: Not significant. ND: Not detectable. -: Not determined. CAMKII: $\mathrm{Ca}^{2+}$-calmodulin-dependent kinase II, Ctrl: Control animals, Def: Vitamin C deficient animals, $p$-CAMKII: phosphorylated $\mathrm{Ca}^{2+}$-calmodulin-dependent kinase II, $p$-synapsin 1 : phosphorylated synapsin, Sev_def: Severely vitamin C deficient animals. 


\subsection{Morphological Data}

No differences between the Ctrl and Sev_def groups were detected in any of the morphological parameters of the apical and the basal dendrites (Figure 5, Table 1), except for a slight decrease in apical dendrite volume in the Sev_def group $(p=0.0488)$. The same was also the case for the Sholl analysis (Figure 6), where severe vitC deficiency did not give rise to any regional changes in the dendrite arbor for basal and apical dendrites.
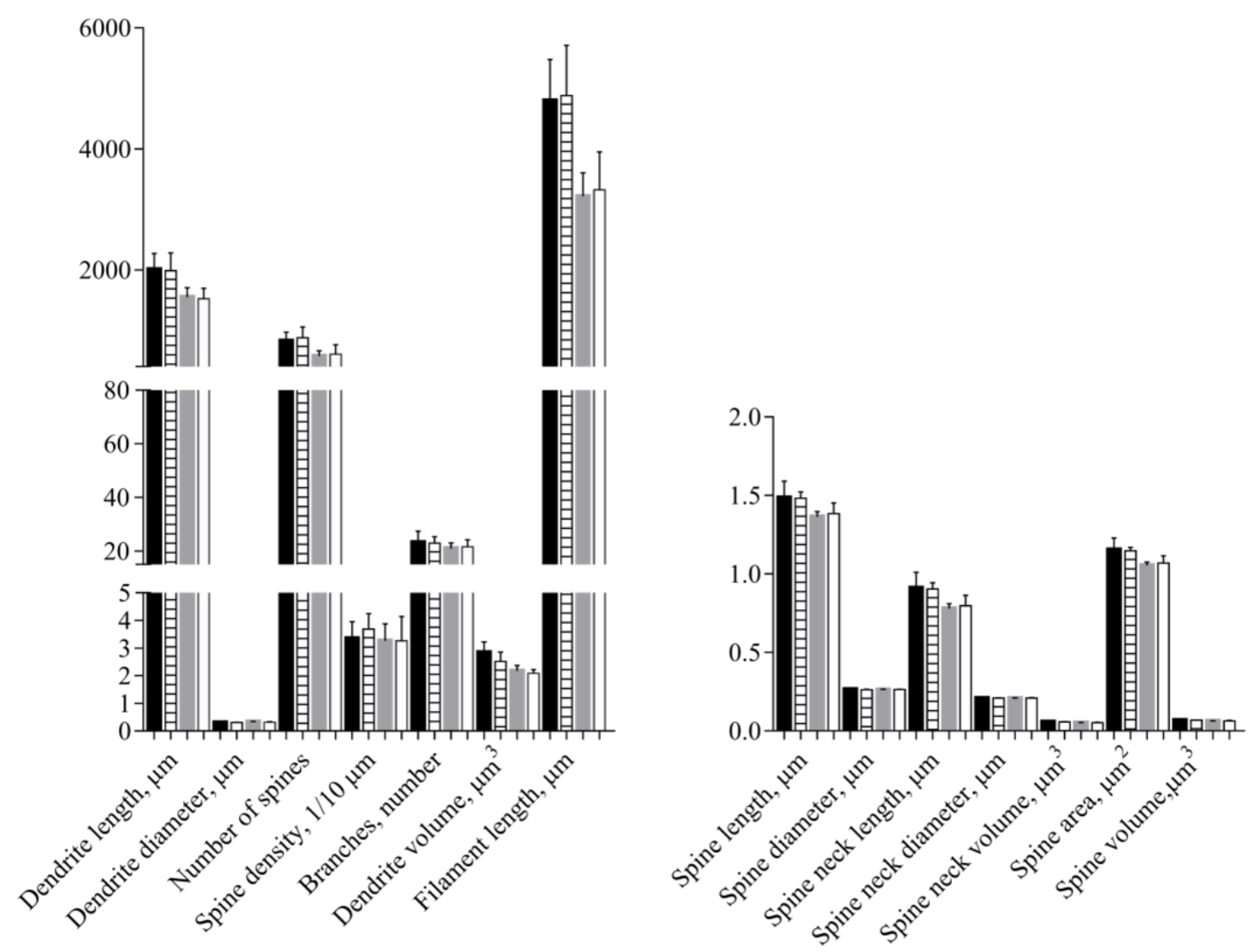

Figure 5. Morphological analyses of apical and basal dendrites of pyramidal neurons in the cornu ammonis 1 of the hippocampus. Control animals (apical-black; basal—gray) and severely vitamin $\mathrm{C}$ deficient animals (apical—horisontal stripes; basal—white). No influence of vitamin C deficiency was detected in the morphological parameters, except for a slight decrease in apical dendrite volume $(p=0.0488)$. $t$-Test or Welch's $t$-test, mean \pm SD. Each experimental group consisted of 10 animals and from each animal 5-7 pyramidal neurons situated within the stratum pyramidale of cornu ammonis 1 were analyzed for morphological changes and the data averaged. 

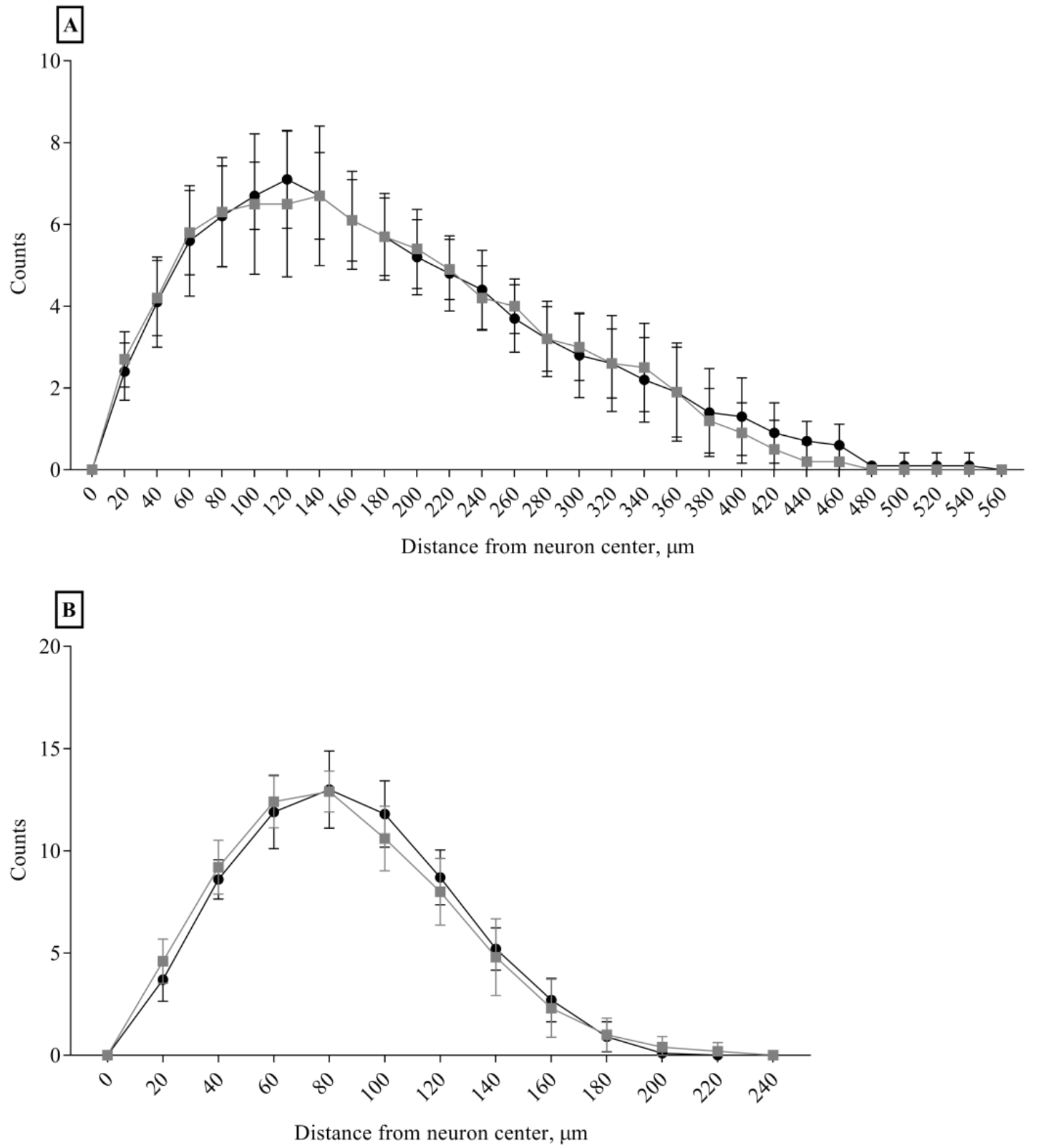

Figure 6. Sholl analysis of apical and basal dendrites of cornu ammonis 1 pyramidal neurons. Apical (A) and basal (B) cornu ammonis 1 pyramidal neuron from control animals (black dots) and severely vitamin C deficient animals (gray squares). No effect of vitC deficiency was detected on the dendrite complexity measured as number of dendrite crossings on concentric circles radiating from the neuronal soma with a continuous increase in the radius of $20 \mu \mathrm{m}$. Two-way repeated measures ANOVA, mean \pm SD. Each experimental group consisted of 10 animals and from each animal 5-7 pyramidal neurons within the stratum pyramidale of cornu ammonis 1 were analyzed for morphological changes and the data averaged.

\section{Discussion}

The dietary vitC levels were reflected in the recorded plasma concentrations and cortical levels of the animals, as expected. A decrease in $\mathrm{BH} 4$ and an increase in $\mathrm{BH} 2 / \mathrm{BH} 4$ ratio were evident in plasma of vitC deficient animals, reflecting that Asc is also a cofactor for the recycling of BH4 $[17,50]$. Though tissue BH4 levels were not measured in this study, the decreased BH4 in plasma may reflect a decrease in cerebral $\mathrm{BH} 4$ levels. Inside the brain, $\mathrm{BH} 4$ is involved in the synthesis of the 
monoaminergic neurotransmitters, e.g., dopamine and norepinephrine [19]. Dopaminergic neurons and receptors have been shown to be involved in spatial memory [56,57], while norepinephrine has been found to be involved with memory consolidation and retrieval in the Hip [58,59]. Deviations in the hippocampal monoamine levels could be a likely contributor to vitC imposed cognitive deficits. Indeed, monoaminergic changes have been reported in a knockout mouse model of vitC deficiency [26,60].

Only limited changes in additional biochemical markers of redox balance were recorded. The Sev_def group was included to assess effects of an increased degree of vitC deficiency and subsequent progressive negative effects compared to Def animals, possibly indicating a dose-dependency in the recorded markers. Dietary regimes similar to those applied in this study have previously been shown to increase DHA\%, as well as other markers of oxidative stress in guinea pigs [20-22]. Contrary to our expectations, and despite a decrease in total vitC levels in the cerebral cortex and an increase in the adrenal DHA\% of the Def and Sev_def groups, the diets of the current study did not impose a degree of deficiency in the brain severe enough to affect the additional redox markers at time of euthanasia. Why this is the case remains speculative but may be due to the genetic variation of the animals, as vitC homeostasis, and possibly also susceptibility to oxidative stress is influenced by genetic differences [61-63]. Thus, it can be surmised that the animals in this study were less susceptible to oxidative stress induced by low dietary vitC compared to previous studies. Still, as vitC has several specific functions, low tissue levels could potentially affect the brain negatively. The present absence of oxidative stress consequently allowed us to investigate a direct influence of vitC deficiency on the BDNF pathway and the morphology of the CA1 pyramidal neurons.

However, since no differences between the experimental groups could be recorded in the markers of synaptic plasticity, no direct impact of decreased vitC on synaptic plasticity can be supported by this study. Consulting previously published findings, it is likely that oxidative stress is imperative for vitC deficiency induced deficits [32,64]. Whether other cellular pathways are directly affected by vitC deficiency remains to be investigated. However, BDNF affects down-stream targets through three alternate routes; the phospholipase $C-\gamma$, the phosphoinositide-3 kinase and the extracellular signal-regulated kinase (ERK) regulated pathway; all leading to transcription factor activation [33]. In vitro, Asc and SVCT2 overexpression have been shown to increase ERK 1/2 phosphorylation [37] known to be important for long term spatial memory formation [65] and sensitive to oxidative stress [66]. Synapsin 1 has several phosphorylation sites, including one activated by ERK 1/2 [67]. Despite an absence of changes in synapsin 1 phosphorylated at the CAMKII site as investigated in the current study [68], it may be speculated that vitC deficiency would decrease ERK1/2 phosphorylation, in turn decreasing presynaptic synapsin 1 phosphorylation and/or impaired postsynaptic transcription and leading to the previously observed decreased spatial memory retention in early life guinea pigs [20].

Except for a slight decrease in apical dendrite volume, CA1 pyramidal neuron morphology was not significantly different in severe vitC deficient animals compared to control counterparts. This contrasts with previous studies investigating vitC and neuronal morphology. In vitro, cultures of hippocampal neurons from SVCT2 knockout mice display decreased dendrite length and number of primary branches [36], while overexpression of the transporter increased branching in neuroblastoma cells [37], supporting that neuronal morphology, in vitro, is influenced by vitC uptake. In vivo, findings from adult Gulo-l- mice further associates total vitC depletion with atrophic neuronal changes, including axonal and dendritic shrinkage in the granule and Purkinje neurons of the cerebellum, in conjunction with increases in oxidative stress, apoptotic markers and inflammation [32]. Other forms of malnutrition, both pre-and postnatal, have been found to alter neuronal morphology in the Hip, supporting that the hippocampal dendritic arbor is sensitive to malnutrition states during development; e.g., iron deficiency inducing reduced CA1 pyramidal neurons dendrite width, spine head diameter and branching, [69], a high fat diet giving rise to decreased dendrite length and branch points as well as indications of decreased spines in basal CA1 pyramidal neurons [70], and iodine deficiency showing decreases in the length and number of basal dendrites [71]. This links malnutrition to deviations in early life development of neuronal and dendrite morphology, promoting neurological deficits with 
putatively negative consequences for brain function i.e., memory deficits [72,73] We hypothesized that vitC deficiency in early life would impose a detrimental effect on overall neuronal morphology, measured as a reduction in dendrite length and branching and an immature or degenerative dendritic spine morphology with alterations in length and reductions in volume and/or area (Table 1) [54,55].

Contrary to our hypothesis, but in line with the protein expression analysis on the included brain samples, no alterations of the measured morphological target points were recorded in the current study. Decreased spine density and dendrite length in CA1 has been shown in induced brain-oxidative stress in vivo [74,75] and in animal models of Alzheimer's disease [76,77], known to display increased oxidative stress during disease progression [78], supporting the association between oxidative stress and impaired CA1 morphology. The absence of morphological differences between experimental groups in the current groups, suggests that vitC deficiency in the brain may require the presence of redox imbalance to impose negative effects on neuronal morphology.

Other subareas and cell types in the Hip are involved in spatial memory and may also be targets of its deficiency-associated memory deficits. The CA1 area selected for the present investigation represents a subdivision of the Hip and the reported absence of altered neuronal morphology does not exclude a vitC deficiency-imposed effect on other areas of the Hip, e.g., the CA3 and dentate gyrus. CA3 pyramidal neurons are involved in retention of spatial memory and in spatial memory recall $[79,80]$, while neurogenesis in the dentate gyrus has also been found to be crucial in spatial memory [81,82]. Whether other hippocampal areas are affected by vitC deficiency remains to be explored. Other cell types within the brain may also be sensitive to vitC deficiency. Astrocytes are key cells in regulation of oxidative stress in the brain and recycle Asc from DHA [83]. They have been shown to influence neurotransmission, synaptic plasticity, learning and memory [84,85] and increased oxidative stress has been found to induce astrocyte dysfunction [86,87]. Astrocytes secrete Asc, when stimulated by glutamate [88], which may be crucial in preventing excitotoxicity otherwise leading to increased neuronal death [36]. Interestingly, increased oxidative stress decreases accumulation of recycled Asc in astrocytes [89], which may lead to increased glutamate-induced excitotoxicity. Indeed, we have previously found lower number of neurons in the Hip in vitC deficient guinea pigs [20]. Thus, disturbances in astrocyte function and impairment of glutamate regulation could be detrimental to the brain and should be investigated further.

\section{Conclusions}

In conclusion, vitC deficiency without ensuing oxidative stress does not seem to decrease synaptic plasticity or CA1 neuronal morphology in young guinea pigs. Other pathways potentially involved with vitC deficiency induced spatial memory deficits should be investigated.

Author Contributions: S.N.H., J.L. and P.T.N. designed the in vivo experiment. The neuronal morphology experiment was designed by S.N.H. and J.R.N. The experimental work was conducted by S.N.H. and J.M.B.J. S.N.H., J.L. and P.T.N. interpreted the data and wrote the draft manuscript. All authors critically revised and approved of the final draft.

Ethical Approval: All applicable international, national, and/or institutional guidelines for the care and use of animals were followed.

Acknowledgments: S.N.H. and J.L. are supported by the LifePharm Centre for In Vivo Pharmacology at University of Copenhagen. The work was funded by the Independent Research Fund Denmark. The funding resources had no involvement in study design, collection, analysis and interpretation of data, in the writing of the article or in the decision to summit the article. The authors wish to thank Joan Frandsen, Ricki Thanning and Helene Andersen for excellent technical assistance.

Conflicts of Interest: The authors declare no conflict of interest.

\section{References}

1. Dobbing, J. Later growth of the brain and its vulnerability. Pediatrics 1974, 53, 2-6. [CrossRef] [PubMed]

2. Ikonomidou, C.; Kaindl, A.M. Neuronal death and oxidative stress in the developing brain. Antioxid. Redox Signal. 2011, 14, 1535-1550. [CrossRef] [PubMed] 
3. Valtorta, F.; Pozzi, D.; Benfenati, F.; Fornasiero, E.F. The synapsins: Multitask modulators of neuronal development. Semin. Cell Dev. Biol. 2011, 22, 378-386. [CrossRef] [PubMed]

4. Tolsa, C.B.; Zimine, S.; Warfield, S.K.; Freschi, M.; Rossignol, A.S.; Lazeyras, F.; Hanquinet, S.; Pfizenmaier, M.; Hüppi, P.S. Early alteration of structural and functional brain development in premature infants born with intrauterine growth restriction. Pediatr. Res. 2004, 56, 132-138. [CrossRef] [PubMed]

5. Morgane, P.J.; Mokler, D.J.; Galler, J.R. Effects of prenatal protein malnutrition on the hippocampal formation. Neurosci. Biobehav. Rev. 2002, 26, 471-483. [CrossRef]

6. Akitake, Y.; Katsuragi, S.; Hosokawa, M.; Mishima, K.; Ikeda, T.; Miyazato, M.; Hosoda, H. Moderate maternal food restriction in mice impairs physical growth, behavior, and neurodevelopment of offspring. Nutr. Res. 2015, 35, 76-87. [CrossRef] [PubMed]

7. Mosdøl, A.; Erens, B.; Brunner, E.J. Estimated prevalence and predictors of vitamin C deficiency within UK's low-income population. J. Public Health 2008, 30, 456-460. [CrossRef] [PubMed]

8. Langlois, K.; Cooper, M.; Colapinto, C.K. Vitamin C status of Canadian adults: Findings from the 2012/2013 Canadian Health Measures Survey. Health Rep. 2016, 27, 3-10. [PubMed]

9. Schüpbach, R.; Wegmüller, R.; Berguerand, C.; Bui, M.; Herter-Aeberli, I. Micronutrient status and intake in omnivores, vegetarians and vegans in Switzerland. Eur. J. Nutr. 2017, 56, 283-293. [CrossRef] [PubMed]

10. Juhl, B.; Lauszus, F.F.; Lykkesfeldt, J. Poor vitamin C status late in pregnancy is associated with increased risk of complications in type 1 diabetic women: A cross-sectional study. Nutrients 2017, 9, 186. [CrossRef] [PubMed]

11. Scaife, A.R.; McNeill, G.; Campbell, D.M.; Martindale, S.; Devereux, G.; Seaton, A. Maternal intake of antioxidant vitamins in pregnancy in relation to maternal and fetal plasma levels at delivery. Br. J. Nutr. 2006, 95, 771-778. [CrossRef] [PubMed]

12. De Oliveira, A.M.; Rondo, P.H.D.; Barros, S.B.D. Concentrations of ascorbic acid in the plasma of pregnant smokers and nonsmokers and their newborns. Int. J. Vitam. Nutr. Res. 2004, 74, 193-198. [CrossRef] [PubMed]

13. Hasselholt, S.; Tveden-Nyborg, P.; Lykkesfeldt, J. Distribution of vitamin C is tissue specific with early saturation of the brain and adrenal glands following differential oral dose regimens in guinea pigs. Br. J. Nutr. 2015, 113, 1539-1549. [CrossRef] [PubMed]

14. Harrison, F.E.; May, J.M. Vitamin C function in the brain: Vital role of the ascorbate transporter SVCT2. Free Radic. Biol. Med. 2009, 46, 719-730. [CrossRef] [PubMed]

15. Hughes, R.E.; Hurley, R.J.; Jones, P.R. Retention of ascorbic acid by guinea pig tissues. Br. J. Nutr. 1971, 26, 433-438. [CrossRef] [PubMed]

16. Lykkesfeldt, J.; Trueba, G.P.; Poulsen, H.E.; Christen, S. Vitamin C deficiency in weanling guinea pigs: Differential expression of oxidative stress and DNA repair in liver and brain. Br. J. Nutr. 2007, 98, 1116-1119. [CrossRef] [PubMed]

17. May, J.M.; Qu, Z.-C.; Meredith, M.E. Mechanisms of ascorbic acid stimulation of norepinephrine synthesis in neuronal cells. Biochem. Biophys. Res. Commun. 2012, 426, 148-152. [CrossRef] [PubMed]

18. Rebec, G.V.; Pierce, R.C. A vitamin as a neuromodulator-Ascorbate release into the extracellular fluid of the brain regulates dopaminergic and glutaminergic transmission. Prog. Neurobiol. 1994, 43, 537-565. [CrossRef]

19. Fitzpatrick, P.F. Tetrahydropterin-dependent amino acid hydroxylases. Annu. Rev. Biochem. 1999, 68, 355-381. [CrossRef] [PubMed]

20. Tveden-Nyborg, P.; Johansen, L.K.; Raida, Z.; Villumsen, C.K.; Larsen, J.O.; Lykkesfeldt, J. Vitamin C deficiency in early postnatal life impairs spatial memory and reduces the number of hippocampal neurons in guinea pigs. Am. J. Clin. Nutr. 2009, 90, 540-546. [CrossRef] [PubMed]

21. Tveden-Nyborg, P.; Vogt, L.; Schjoldager, J.G.; Jeannet, N.; Hasselholt, S.; Paidi, M.D.; Christen, S.; Lykkesfeldt, J. Maternal vitamin C deficiency during pregnancy persistently impairs hippocampal neurogenesis in offspring of guinea pigs. PLOS ONE 2012, 7, e48488. [CrossRef] [PubMed]

22. Paidi, M.D.; Schjoldager, J.G.; Lykkesfeldt, J.; Tveden-Nyborg, P. Prenatal vitamin C deficiency results in differential levels of oxidative stress during late gestation in foetal guinea pig brains. Redox Biol. 2014, 2, 361-367. [CrossRef] [PubMed]

23. Sotiriou, S.; Gispert, S.; Cheng, J.; Wang, Y.H.; Chen, A.; Hoogstraten-Miller, S.; Miller, G.F.; Kwon, O.; Levine, M.; Guttentag, S.H.; et al. Ascorbic-acid transporter Slc23a1 is essential for vitamin C transport into the brain and for perinatal survival. Nat. Med. 2002, 8, 514-517. [CrossRef] [PubMed] 
24. Harrison, F.E.; Dawes, S.M.; Meredith, M.E.; Babaev, V.R.; Li, L.; May, J.M. Low vitamin C and increased oxidative stress and cell death in mice that lack the sodium-dependent vitamin C. transporter SVCT2. Free Radic. Biol. Med. 2010, 49, 821-829. [CrossRef] [PubMed]

25. Harrison, F.E.; Yu, S.S.; Van Den Bossche, K.L.; Li, L.Y.; May, J.M.; McDonald, M.P. Elevated oxidative stress and sensorimotor deficits but normal cognition in mice that cannot synthesize ascorbic acid. J. Neurochem. 2008, 106, 1198-1208. [CrossRef] [PubMed]

26. Ward, M.S.; Lamb, J.; May, J.M.; Harrison, F.E. Behavioral and monoamine changes following severe vitamin C deficiency. J. Neurochem. 2013, 124, 363-375. [CrossRef] [PubMed]

27. Beutler, L.R.; Eldred, K.C.; Quintana, A.; Keene, C.D.; Rose, S.E.; Postupna, N.; Montine, T.J.; Palmiter, R.D. Severely impaired learning and altered neuronal morphology in mice lacking NMDA receptors in medium spiny neurons. PLoS ONE 2011, 6, e28168. [CrossRef] [PubMed]

28. Groc, L.; Gustafsson, B.; Hanse, E. In vivo evidence for an activity-independent maturation of AMPA/NMDA signaling in the developing hippocampus. Neuroscience 2003, 121, 65-72. [CrossRef]

29. Penzes, P.; Cahill, M.E.; Jones, K.A.; VanLeeuwen, J.-E.; Woolfrey, K.M. Dendritic spine pathology in neuropsychiatric disorders. Nat. Neurosci. 2011, 14, 285-293. [CrossRef] [PubMed]

30. Kulkarni, V.A.; Firestein, B.L. The dendritic tree and brain disorders. Mol. Cell. Neurosci. 2012, 50, 10-20. [CrossRef] [PubMed]

31. Grant, M.M.; Barber, V.S.; Griffiths, H.R. The presence of ascorbate induces expression of brain derived neurotrophic factor in SH-SY5Y neuroblastoma cells after peroxide insult, which is associated with increased survival. Proteomics 2005, 5, 534-540. [CrossRef] [PubMed]

32. Kim, H.; Kim, Y.; Bae, S.; Lim, S.H.; Jang, M.; Choi, J.; Jeon, J.; Hwang, Y.I.; Kang, J.S.; Lee, W.J. Vitamin C deficiency causes severe defects in the development of the neonatal cerebellum and in the motor behaviors of Gulo ${ }^{-/-}$mice. Antioxid. Redox Signal. 2015, 23, 1270-1283. [CrossRef] [PubMed]

33. Cunha, C.; Brambilla, R.; Thomas, K.L. A simple role for BDNF in learning and memory? Front. Mol. Neurosci. 2010, 3, 1. [CrossRef] [PubMed]

34. Martin, S.J.; Grimwood, P.D.; Morris, R.G.M. Synaptic plasticity and memory: An evaluation of the hypothesis. Annu. Rev. Neurosci. 2000, 23, 649-711. [CrossRef] [PubMed]

35. He, X.-B.; Kim, M.; Kim, S.-Y.; Yi, S.-H.; Rhee, Y.-H.; Kim, T.; Lee, E.-H.; Park, C.-H.; Dixit, S.; Harrison, F.E.; et al. Vitamin $\mathrm{C}$ facilitates dopamine neuron differentiation in fetal midbrain through TET1- and JMJD3-dependent epigenetic control manner. Stem Cells 2015, 33, 1320-1332. [CrossRef] [PubMed]

36. Qiu, S.; Li, L.; Weeber, E.J.; May, J.M. Ascorbate transport by primary cultured neurons and its role in neuronal function and protection against excitotoxicity. J. Neurosci. Res. 2007, 85, 1046-1056. [CrossRef] [PubMed]

37. Salazar, K.; Martinez, M.; Ulloa, V.; Bertinat, R.; Martinez, F.; Jara, N.; Espinoza, F.; Bongarzone, E.R.; Nualart, F. SVCT2 overexpression in neuroblastoma cells induces cellular branching that is associated with ERK signaling. Mol. Neurobiol. 2016, 53, 6668-6679. [CrossRef] [PubMed]

38. Balleine, B.W.; Delgado, M.R.; Hikosaka, O. The role of the dorsal striatum in reward and decision-making. J. Neurosci. 2007, 27, 8161-8165. [CrossRef] [PubMed]

39. Fuster, J.M. Executive frontal functions. Exp. Brain Res. 2000, 133, 66-70. [CrossRef] [PubMed]

40. Burgess, N.; Maguire, E.A.; O'Keefe, J. The human hippocampus and spatial and episodic memory. Neuron 2002, 35, 625-641. [CrossRef]

41. Sanhueza, M.; Fernandez, G. CaMKII: A master functional and structural molecule in synaptic plasticity and memory. In Novel Mechanisms of Memory; Giese, K.P., Radwanska, K., Eds.; Springer International Publishing: Cham, Switzerland, 2016; pp. 43-66.

42. Lee, S.G.; Yoo, D.Y.; Jung, H.Y.; Nam, S.M.; Kim, J.W.; Choi, J.H.; Yi, S.S.; Won, M.-H.; Yoon, Y.S.; Hwang, I.K.; et al. Neurons in the hippocampal CA1 region, but not the dentate gyrus, are susceptible to oxidative stress in rats with streptozotocin-induced type 1 diabetes. Neural Regen. Res. 2015, 10, 451-456. [PubMed]

43. Wang, X.; Michaelis, E.K. Selective neuronal vulnerability to oxidative stress in the brain. Front. Aging Neurosci. 2010, 2, 12. [CrossRef] [PubMed]

44. Goodrich-Hunsaker, N.J.; Hunsaker, M.R.; Kesner, R.P. The interactions and dissociations of the dorsal hippocampus subregions: How the dentate gyrus, CA3, and CA1 process spatial information. Behav. Neurosci. 2008, 122, 16-26. [CrossRef] [PubMed] 
45. Tsien, J.Z.; Huerta, P.T.; Tonegawa, S. The essential role of hippocampal CA1 NMDA receptor-dependent synaptic plasticity in spatial memory. Cell 1996, 87, 1327-1338. [CrossRef]

46. Schjoldager, J.G.; Paidi, M.D.; Lindblad, M.M.; Birck, M.M.; Kjærgaard, A.B.; Dantzer, V.; Lykkesfeldt, J.; Tveden-Nyborg, P. Maternal vitamin C deficiency during pregnancy results in transient fetal and placental growth retardation in guinea pigs. Eur. J. Nutr. 2014, 54, 667-676. [CrossRef] [PubMed]

47. Paxinos, G. The Rat Brain in Stereotaxic Coordinates, 4th ed.; Academic Press: San Diego, CA, USA; London, UK, 1998.

48. Lykkesfeldt, J. Determination of ascorbic acid and dehydroascorbic acid in biological samples by high-performance liquid chromatography using subtraction methods: Reliable reduction with tris[2-carboxyethyl]phosphine hydrochloride. Anal. Biochem. 2000, 282, 89-93. [CrossRef] [PubMed]

49. Lykkesfeldt, J. Measurement of ascorbic acid and dehydroascorbic acid in biological samples. Curr. Protoc. Toxicol. 2002, 12. [CrossRef]

50. Mortensen, A.; Hasselholt, S.; Tveden-Nyborg, P.; Lykkesfeldt, J. Guinea pig ascorbate status predicts tetrahydrobiopterin plasma concentration and oxidation ratio in vivo. Nutr. Res. 2013, 33, 859-867. [CrossRef] [PubMed]

51. Søgaard, D.; Lindblad, M.M.; Paidi, M.D.; Hasselholt, S.; Lykkesfeldt, J.; Tveden-Nyborg, P. In vivo vitamin $\mathrm{C}$ deficiency in guinea pigs increases ascorbate transporters in liver but not kidney and brain. Nutr. Res. 2014, 34, 639-645. [CrossRef] [PubMed]

52. Chen, F.; du Jardin, K.G.; Waller, J.A.; Sanchez, C.; Nyengaard, J.R.; Wegener, G. Vortioxetine promotes early changes in dendritic morphology compared to fluoxetine in rat hippocampus. Eur. Neuropsychopharmacol. 2016, 26, 234-245. [CrossRef] [PubMed]

53. Paternoster, V.; Rajkumar, A.P.; Nyengaard, J.R.; Børglum, A.D.; Grove, J.; Christensen, J.H. The importance of data structure in statistical analysis of dendrite spine morphology. J. Neurosci. Methods 2017, 296, 93-98. [CrossRef] [PubMed]

54. Hering, H.; Sheng, M. Dentritic spines: Structure, dynamics and regulation. Nat. Rev. Neurosci. 2001, 2, 880-888. [CrossRef] [PubMed]

55. Fiala, J.C.; Spacek, J.; Harris, K.M. Dendritic spine pathology: Cause or consequence of neurological disorders? Brain Res. Brain Res. Rev. 2002, 39, 29-54. [CrossRef]

56. Da Silva, W.C.N.; Köhler, C.C.; Radiske, A.; Cammarota, M. D1/D5 dopamine receptors modulate spatial memory formation. Neurobiol. Learn. Mem. 2012, 97, 271-275. [CrossRef] [PubMed]

57. McNamara, C.G.; Tejero-Cantero, Á.; Trouche, S.; Campo-Urriza, N.; Dupret, D. Dopaminergic neurons promote hippocampal reactivation and spatial memory persistence. Nat. Neurosci. 2014, 17, 1658-1660. [CrossRef] [PubMed]

58. Murchison, C.F.; Zhang, X.-Y.; Zhang, W.-P.; Ouyang, M.; Lee, A.; Thomas, S.A. A distinct role for norepinephrine in memory retrieval. Cell 2004, 117, 131-143. [CrossRef]

59. Murchison, C.F.; Schutsky, K.; Jin, S.H.; Thomas, S.A. Norepinephrine and B1-adrenergic signaling facilitate activation of hippocampal CA1 pyramidal neurons during contextual memory retrieval. Neuroscience 2011, 181, 109-116. [CrossRef] [PubMed]

60. Meredith, M.E.; May, J.M. Regulation of embryonic neurotransmitter and tyrosine hydroxylase protein levels by ascorbic acid. Brain Res. 2013, 1539, 7-14. [CrossRef] [PubMed]

61. Michels, A.J.; Hagen, T.M.; Frei, B. Human genetic variation influences vitamin $C$ homeostasis by altering vitamin C transport and antioxidant enzyme function. Annu. Rev. Nutr. 2013, 33, 45-70. [CrossRef] [PubMed]

62. Wang, X.; Chen, H.; Liu, J.; Ouyang, Y.; Wang, D.; Bao, W.; Liu, L. Association between the NF-E2 related factor 2 gene polymorphism and oxidative stress, anti-oxidative status, and newly-diagnosed type 2 diabetes mellitus in a Chinese population. Int. J. Mol. Sci. 2015, 16, 16483-16496. [CrossRef] [PubMed]

63. Crawford, A.; Fassett, R.G.; Geraghty, D.P.; Kunde, D.A.; Ball, M.J.; Robertson, I.K.; Coombes, J.S. Relationships between single nucleotide polymorphisms of antioxidant enzymes and disease. Gene 2012, 501, 89-103. [CrossRef] [PubMed]

64. Hossain, S.; Bhowmick, S.; Jahan, S.; Rozario, L.; Sarkar, M.; Islam, S.; Basunia, M.A.; Rahman, A.; Choudhury, B.K.; Shahjalal, H. Maternal lead exposure decreases the levels of brain development and cognition-related proteins with concomitant upsurges of oxidative stress, inflammatory response and apoptosis in the offspring rats. Neurotoxicology 2016, 56, 150-158. [CrossRef] [PubMed] 
65. Blum, S.; Moore, A.N.; Adams, F.; Dash, P.K. A mitogen-activated protein kinase cascade in the CA1/CA2 subfield of the dorsal hippocampus is essential for long-term spatial memory. J. Neurosci. 1999, 19, 3535-3544. [CrossRef] [PubMed]

66. Crivello, N.A.; Rosenberg, I.H.; Shukitt-Hale, B.; Bielinski, D.; Dallal, G.E.; Joseph, J.A. Aging modifies brain region-specific vulnerability to experimental oxidative stress induced by low dose hydrogen peroxide. Age 2007, 29, 191-203. [CrossRef] [PubMed]

67. Jovanovic, J.N.; Czernik, A.J.; Fienberg, A.A.; Greengard, P.; Sihra, T.S. Synapsins as mediators of BDNF-enhanced neurotransmitter release. Nat. Neurosci. 2000, 3, 323-329. [CrossRef] [PubMed]

68. Cesca, F.; Baldelli, P.; Valtorta, F.; Benfenati, F. The synapsins: Key actors of synapse function and plasticity. Prog. Neurobiol. 2010, 91, 313-348. [CrossRef] [PubMed]

69. Brunette, K.E.; Tran, P.V.; Wobken, J.D.; Carlson, E.S.; Georgieff, M.K. Gestational and neonatal iron deficiency alters apical dendrite structure of CA1 pyramidal neurons in adult rat hippocampus. Dev. Neurosci. 2010, 32, 238-248. [CrossRef] [PubMed]

70. Janthakhin, Y.; Rincel, M.; Costa, A.-M.; Darnaudéry, M.; Ferreira, G. Maternal high-fat diet leads to hippocampal and amygdala dendritic remodeling in adult male offspring. Psychoneuroendocrinology 2017, 83, 49-57. [CrossRef] [PubMed]

71. Min, H.; Wang, Y.; Dong, J.; Wang, Y.; Yu, Y.; Shan, Z.; Xi, Q.; Teng, W.; Chen, J. Effects of maternal marginal iodine deficiency on dendritic morphology in the hippocampal CA1 pyramidal neurons in rat offspring. Neuromol. Med. 2016, 18, 203-215. [CrossRef] [PubMed]

72. Copf, T. Impairments in dendrite morphogenesis as etiology for neurodevelopmental disorders and implications for therapeutic treatments. Neurosci. Biobehav. Rev. 2016, 68, 946-978. [CrossRef] [PubMed]

73. Tata, D.A.; Anderson, B.J. The effects of chronic glucocorticoid exposure on dendritic length, synapse numbers and glial volume in animal models: Implications for hippocampal volume reductions in depression. Physiol. Behav. 2010, 99, 186-193. [CrossRef] [PubMed]

74. Gupta, R.C.; Milatovic, S.; Dettbarn, W.-D.; Aschner, M.; Milatovic, D. Neuronal oxidative injury and dendritic damage induced by carbofuran: Protection by memantine. Toxicol. Appl. Pharmacol. 2007, 219, 97-105. [CrossRef] [PubMed]

75. Won, S.J.; Yoo, B.H.; Kauppinen, T.M.; Choi, B.Y.; Kim, J.H.; Jang, B.G.; Lee, M.W.; Sohn, M.; Liu, J.; Swanson, R.A.; et al. Recurrent/moderate hypoglycemia induces hippocampal dendritic injury, microglial activation, and cognitive impairment in diabetic rats. J. Neuroinflammation 2012, 9, 182. [CrossRef] [PubMed]

76. Perez-Cruz, C.; Nolte, M.W.; van Gaalen, M.M.; Rustay, N.R.; Termont, A.; Tanghe, A.; Kirchhoff, F.; Ebert, U. Reduced spine density in specific regions of CA1 pyramidal neurons in two transgenic mouse models of Alzheimer's disease. J. Neurosci. 2011, 31, 3926-3934. [CrossRef] [PubMed]

77. Sun, G.-Z.; He, Y.-C.; Ma, X.K.; Li, S.-T.; Chen, D.-J.; Gao, M.; Qiu, S.-F.; Yin, J.-X.; Shi, J.; Wu, J. Hippocampal synaptic and neural network deficits in young mice carrying the human APOE4 gene. CNS. Neurosci. Ther. 2017, 23, 748-758. [CrossRef] [PubMed]

78. Barnham, K.J.; Masters, C.L.; Bush, A.I. Neurodegenerative diseases and oxidative stress. Nat. Rev. Drug Discov. 2004, 3, 205-214. [CrossRef] [PubMed]

79. Steffenach, H.A.; Sloviter, R.S.; Moser, E.I.; Moser, M.B. Impaired retention of spatial memory after transection of longitudinally oriented axons of hippocampal CA3 pyramidal cells. Proc. Natl. Acad. Sci. USA 2002, 99, 3194-3198. [CrossRef] [PubMed]

80. Schlesiger, M.I.; Cressey, J.C.; Boublil, B.; Koenig, J.; Melvin, N.R.; Leutgeb, J.K.; Leutgeb, S. Hippocampal activation during the recall of remote spatial memories in radial maze tasks. Neurobiol. Learn. Mem. 2013, 106, 324-333. [CrossRef] [PubMed]

81. Jessberger, S.; Clark, R.E.; Broadbent, N.J.; Clemenson, G.D.; Consiglio, A.; Lie, D.C.; Squire, L.R.; Gage, F.H. Dentate gyrus-specific knockdown of adult neurogenesis impairs spatial and object recognition memory in adult rats. Learn. Mem. 2009, 16, 147-154. [CrossRef] [PubMed]

82. Snyder, J.S.; Hong, N.S.; McDonald, R.J.; Wojtowicz, J.M. A role for adult neurogenesis in spatial long-term memory. Neuroscience 2005, 130, 843-852. [CrossRef] [PubMed]

83. Nualart, F.; Mack, L.; Garcia, A.; Cisternas, P.; Bongarzone, E.R.; Heitzer, M.; Jara, N.; Martinez, F.; Ferrada, L.; Espinoza, F.; et al. Vitamin C transporters, recycling and the bystander effect in the nervous system: SVCT2 versus GLUTs. J. Stem Cell Res. Ther. 2014, 4, 209. [CrossRef] [PubMed] 
84. Ben Menachem-Zidon, O.; Avital, A.; Ben-Menahem, Y.; Goshen, I.; Kreisel, T.; Shmueli, E.M.; Segal, M.; Ben Hur, T.; Yirmiya, R. Astrocytes support hippocampal-dependent memory and long-term potentiation via interleukin-1 signaling. Brain Behav. Immun. 2011, 25, 1008-1016. [CrossRef] [PubMed]

85. Ota, Y.; Zanetti, A.T.; Hallock, R.M. The role of astrocytes in the regulation of synaptic plasticity and memory formation. Neural Plast. 2013, 2013, 11. [CrossRef] [PubMed]

86. Volterra, A.; Trotti, D.; Tromba, C.; Floridi, S.; Racagni, G. Glutamate uptake inhibition by oxygen free radicals in rat cortical astrocytes. J. Neurosci. 1994, 14, 2924-2932. [CrossRef] [PubMed]

87. Crowe, E.P.; Tuzer, F.; Gregory, B.D.; Donahue, G.; Gosai, S.J.; Cohen, J.; Leung, Y.Y.; Yetkin, E.; Nativio, R.; Wang, L.-S.; et al. Changes in the transcriptome of human astrocytes accompanying oxidative stress-induced senescence. Front. Aging Neurosci. 2016, 8, 208. [CrossRef] [PubMed]

88. Wilson, J.X.; Peters, C.E.; Sitar, S.M.; Daoust, P.; Gelb, A.W. Glutamate stimulates ascorbate transport by astrocytes. Brain Res. 2000, 858, 61-66. [CrossRef]

89. Daskalopoulos, R.; Korcok, J.; Tao, L.; Wilson, J.X. Accumulation of intracellular ascorbate from dehydroascorbic acid by astrocytes is decreased after oxidative stress and restored by propofol. Glia 2002, 39, 124-132. [CrossRef] [PubMed]

(C) 2018 by the authors. Licensee MDPI, Basel, Switzerland. This article is an open access article distributed under the terms and conditions of the Creative Commons Attribution (CC BY) license (http:/ / creativecommons.org/licenses/by/4.0/). 